Article

\title{
The Self-Organizing City and the Architecture of Metabolism: An Architectural Critique on Urban Growth and Reorganization
}

\author{
Cemaliye Eken * and Resmiye Alpar Atun \\ Department of Architecture, Faculty of Architecture, Eastern Mediterranean University, \\ Famagusta 99450, Turkey; resmiye.alpar@emu.edu.tr \\ * Correspondence: cemaliye.eken@emu.edu.tr
}

Received: 19 July 2019; Accepted: 24 September 2019; Published: 26 September 2019

\begin{abstract}
Over decades, cities have undergone rapid urbanization and uncontrolled urban growth. The need for future cities to operate as adaptable complex systems has generated an interest in the self-organizing resilient city. The main aim of the study is to find ways of conceptualizing self-organizing the resilient city as an emerging field of research for urban design and architectural theory. Based on these assumptions, an integrated relationship between architecture and urban design are seen as potential catalysts for absorbing the uncertainty and disturbances of urban growth and preparing the structure, function, and identity of a city as a self-organizing system that can continuously and freely adapt to changes. The paper seeks to determine the role of architecture in urban design as a main key for facilitating a self-organizing system. A systematic theoretical research method was used to describe resilience theory and self-organizing systems within an adaptive cycle and hierarchical thinking across scales. The study then sought to identify the earliest point that architectural theory conceptualized future cities from the perspective of self-organizing systems. The Metabolism movement was chosen to provide a basis for the discussion of the study. Cities as self-organizing systems need to be considered through cross-scale interactions. For a self-organizing resilient city, the inter-reliance between architecture and urban design drive the main inputs to the system.
\end{abstract}

Keywords: resilience; self-organizing city; adaptive cycle; cross-scale interactions; urban growth; renewal; metabolism movement; urban space; architecture

\section{Introduction}

In the 1970s, the terms "self-organizing" and "resilience" were first used in ecology to explain the adaptive capacity of species in ecosystems [1-3]. Resilience is defined as the adaptability and capacity of a system to cope with external stresses in case of a disturbance. The domain of resilience theory elevates the idea of assessing a self-organizing attitude to change. Self-organization is a mechanism of progressive adaption to a certain change. In fact, it is a process contained by cross-scale interactions that enable the system to self-organize [4]. In ecology, a self-organizing resilient ecosystem recognizes non-generic knowledge as an adaptable response to the process of transformation. Anticipating a change upon adaptation is crucial, while learning from the disturbance accomplishes the ability of bouncing-back for the reorganization of the system [5]. The resilience concept significantly unifies the following features $[1,6,7]$ :

(i) If a system still remains the same after a shock of change;

(ii) If a system builds to the extent that the system has the ability to self-organize;

(iii) If a system has the ability to learn and facilitate adaptation. 
The integrated form of the terms self-organizing and resilience has become a key concept in urban studies when cities have been described as the best outcome of a socio-ecological system [8].

Table 1 summarizes the theoretical frameworks underpinning resilience and self-organizing in urban studies. According to Walker et al., cities should be endorsed with resilience thinking by considering urban transformation [2]. They also explained that cities are part of socio-ecological systems, which also demonstrate essential domains to self-organize upon urban transformation by considering the resilience of adaptive capacity. Batty and Marshall viewed the resilience of cities within the context of inter-reliant and diverse dynamics at subsystems level. They stressed that a city is the whole of its subsystems, which could indicate resilience at the internal structure of the system. Moreover, they signified that indicating cities in resilience thinking is dependent on the existence and continuity of multiple-stability states across diverse variables [9]. Ernstson et al. examined resilience thinking for transforming urban areas. According to them, the transforming urban areas could process adaptation by considering the potential of innovative environments (technological development). In the context of self-organizing, technological innovations are seen as essential for urban resilience [10]. Hodson and Marvin focused on the importance and the role of the transitions at local scales, which provide the potential to define the cause/s stressing the system stability. Local scale and elaboration of transition at this scale are seen as essential for urban resilience [11].

Table 1. Theoretical frameworks linking resilience and self-organizing systems with urban studies.

\begin{tabular}{clll}
\hline Theorists and Researches & & \multicolumn{1}{c}{ Approach } \\
\hline Walker et.al [2] & $n$ & $\begin{array}{l}\text { A city as a part of socio-ecological systems } \\
\text { Demonstrate essential domains to self-organize themselves upon urban transformation } \\
\text { by considering resilience of adaptive capacity. }\end{array}$ \\
Batty and Marshall [9] & $n$ & $\begin{array}{l}\text { A city is the whole of its subsystems } \\
\text { Cities within the opportunities of inter-reliant and diverse dynamics at subsystems } \\
\text { Indicating cities in resilience thinking is dependent on the existence and continuity of } \\
\text { multiple-stability states across diverse variables at subsystems }\end{array}$ \\
& $n$ & $n$ & $\begin{array}{l}\text { The resilience thinking for transforming urban areas } \\
\text { Urban systems at transforming urban areas could process adaptation by considering } \\
\text { potentiality of innovative environment (technological development) }\end{array}$ \\
Ernstson et al. [10] & $n$ & $\begin{array}{l}\text { Local scale and elaboration of transition at this scale is seen essential for urban resilience } \\
\text { A need to determine the importance and the role of the transitions at local scales } \\
\text { Local scales provide potentiality to define the cause/s stressing the system stability }\end{array}$ \\
\hline
\end{tabular}

Over the years, cities have been heavily exposed to rapid urban development [12,13]. However, they have limited capacity to reorganize their built environment according to the requirements that evolve from rapid urbanization and transformation. A city as a self-organizing system should await future alerts, uncertain events and the potential for change. The key aspect of a self-organizing resilient city concept requires developing applicable design approaches in city planning that could formulate an organizational (cyclical) adaptation towards developing the contemporary city. The dynamics of successful adaptation of a city into a self-organizing resilient system yield an important avenue for present and future city planning and architecture research, especially when architects began to seek alternative architectural and urban forms that would offer resilience and reorganization. However, many of the studies reinforce resilience theory by tracing back in other disciplines, where the significance of the self-organizing notion and the role of architecture together with urban design and planning are mainly unnoticed [14]. The problem was not the concept of the resilience notion, or the self-organizing system, but the conceptual translation of these as one approach into the architecture and urban design, in which architecture is considered as a complementary scale. 
To conceptualize cities as self-organizing resilient systems, they need to be considered at various scales, and the interaction between these scales must be identified. This study seeks to determine the role and importance of architecture as a complementary scale to be considered for facilitating a self-organizing system, which in this case is the city. The purpose of the paper is to conceptualize a self-organizing resilient city by considering architecture as a fundamental component of scale that could anticipate adaptability at smaller scales and result in the reorganization of the system toward urban growth. The aim of the study is to understand the interdependent interactions across scales for self-organizing resilient systems and to elaborate the role and importance of architecture as the small-scale component of the system as a whole. In order to achieve this aim, the following research questions helped to form the aim and objective of the study:

(1) What is self-organization and how was this mechanism defined within resilience theory?

(2) What are the domains of self-organizing systems that indicate resilience?

(3) What kind of tools can be used to determine the relations' across-scales in a self-organizing system?

(4) How was the self-organizing resilient system at the city scale understood within the intersection of architecture and urban design?

(5) What is the relationship between architecture and urban design that would help to conceptualize a self-organizing resilient city approach?

In this study, systematic theoretical research was carried out on the research focus. As the first step of the method, the paper discusses resilience theory in order to construct a basis for a theoretical framework. Second, a theoretical framework that relates the resilience and self-organizing system together at the city scale is developed by considering the intersection between architecture and urban design. The former, which is referred to as the small scale, and the latter referred to as the larger scale of the city, is developed upon an adaptive cycle approach. The intervention of the adaptive cycle approach as a tool that allows for an examination of these existing and emerging relations across scales that are essential to facilitate a long-run self-organizing resilient system. In order to trace the concept of self-organizing resilient cities, the Metabolist movement was seen as the initial creation of self-organizing and resilience thinking at the city scale by considering the architecture and urban design intersection within a metabolic adaptive cycle model [2]. Based on the findings of systematic theoretical survey, the study develops a framework on interdependent relations between architecture and urban design to self-organization of cities (Figure 1). 


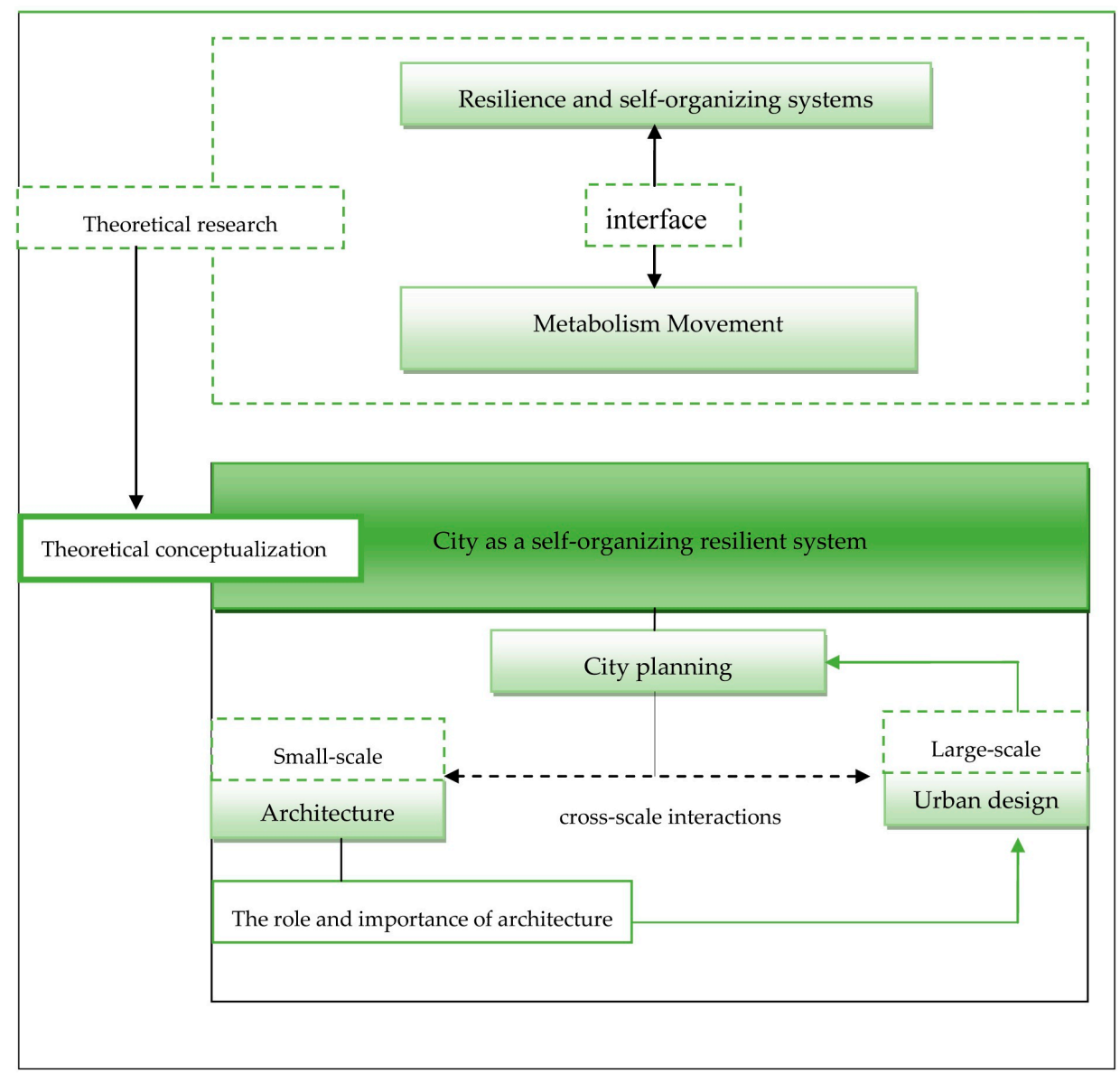

Figure 1. Research design of the study.

\section{Methodology}

The definition of resilience theory and its connection to self-organizing systems provide a framework for conceptualizing cities themselves as self-organizing systems. The cross-scale interactions between architecture and urban design are seen as essential for building a self-organizing system that proposes cyclical adaptation as a response to urban growth. For urban design practitioners, planners, architects, and other related disciplines, the concept of self-organizing resilient cities could provide new ways, perspectives, and influences to understand the built environment as an adaptive system within urban growth and transformation.

\subsection{Methods and Research Design}

\subsubsection{Theoretical Research}

The notion of self-organization and resilience as one integrated concept is primarily very abstract and descriptive. Unwittingly, most resilience studies are not mutually exclusive. The pathway of the terms resilience and self-organizing predicted by each proposition refers to different meanings in different disciplines (Figure 2). Therefore, it is not very clear how to generate an architectural and urban design approach in relation to resilience and self-organizing thinking at the city scale. 


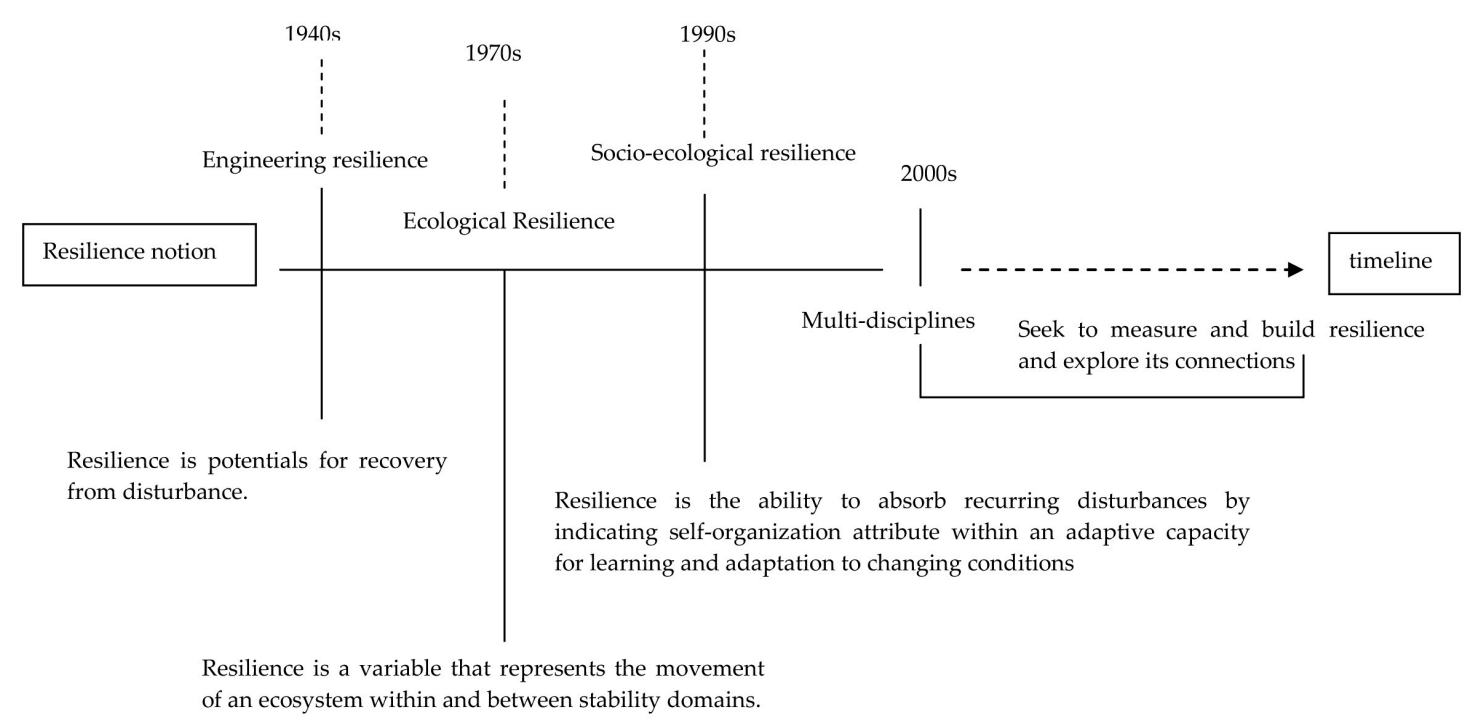

Figure 2. The pathway of the terms resilience and self-organizing in different disciplines [15].

The study focuses to conceptualize a self-organizing resilient city by considering the interdependent interactions across scales, which are architecture and urban design. It aims to indicate architecture as the fundamental scale that could anticipate adaptability for self-organization toward urban growth. The first step is to define the domains of self-organizing resilient cities that addresses adaptive cycle and its hierarchical thinking principle. The next step is to determine the role and significance of architecture throughout the research focus. This was undertaken by systematic theoretical research. To ensure the quality of the theoretical research, the literature review includes several research works, books, published articles, and conference papers.

A systematic (grounded) methodology with explanatory research was carried out in the research design of the study [16-20]. Three types of theoretical research techniques made it possible to assemble the research design and gather the essential data. As a first step, the descriptive theory research method was applied to describe the particular characteristics of resilience theory and self-organizing systems [21]. The key words used to explore the literature included resilience and self-organizing [22]. So as to aid in the conceptualization of self-organizing resilience cities by considering architecture as the complementary scale, we intentionally considered a survey of past practices in architecture. The survey is conducted with the key words included resilience, cities as self-organizing systems, adaptive cycle, architecture, urban design, and future cities. A survey of architecture movements revealed that the Metabolist movement that spanned the 1950s, 60s, and 70s revealed a connection between their outputs and the notion of the self-organizing resilient city concept, which emphasized the interaction between architecture and urban design in an adaptive cycle model [9]. As third step, explanatory theory was generated based on a qualitative correlation between the Metabolists's self-organizing resilient city conceptions for modern day practice [20]. A qualitative correlation acts as a bridge to determine the importance of architecture as an essential scale that could lead the urban space to become an adaptive system accommodating urban growth [23]. This allowed for reinforcing architecture, the most important scale of cross-scale interactions to be considered from the point of view creating an adaptive genetic, which was then linked to the self-organization of the system whole. Furthermore, it opens up a new perspective on thinking cities as a self-organizing system, which is a process-oriented product formed through cross-scale interactions. The research phases are as follows in Figure 3. 


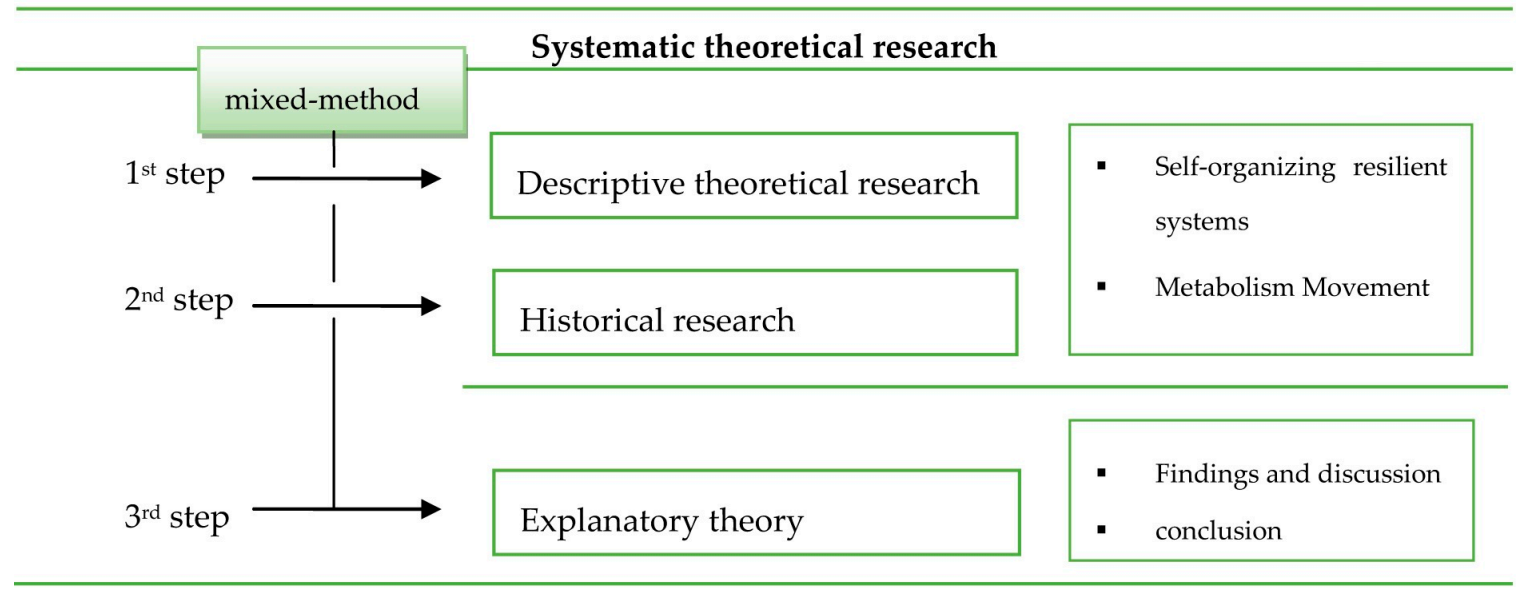

Figure 3. Research phases.

\subsubsection{Reading from Past Visions}

In this research, reading from past visions as a method is included in order to generate a historical relation with the concepts that are discussed $[24,25]$. Furthermore, it can provide a complementary basis for exploring the inter-reliant link between architecture and urban design in the conceptual generalization of a self-organizing approach to cities. The Metabolism movement aimed to conceptualize future cities in the framework of self-organizing systems based on design-driven built environments that could adaptively respond to the changing (future) needs of urban growth.

The future city proposals and projects of the Metabolism movement remained as conceptual, with many unbuilt projects. Therefore, theoretical reading of the Metabolism movement is drawn from academic publications, books, magazines, brochures, online databases, and theses. In the context of the research focus, the literature review pursued answers to the followed questions:

(1) How were the terms "self-organizing" and "resilience" indicated in the metaphoric adaptive cycle model of Metabolism?

(2) What principles of hierarchical thinking to be used in urban design were promoted to build cities freely in order to adapt to urban growth?

(3) How was the built environment architecturally decoded to allow an entire adaptation to change?

(4) What were the design-driven schemes pursued to enable the urban artifacts (buildings) able to avoid the loss of resilience when necessary?

\section{Domains of a Self-Organizing Resilient System}

\subsection{Adaptive Cycle}

The adaptive cycle explains the adaptive capacity that is drawn from the cross-scale interactions of a complex system [26,27]. The adaptive cycle in complex systems embodies cross-scale relationships, where the system explores long-run stability by creating options for innovation towards transformation in shorter times [5]. The adaptive cycle presents four distinct phases to define conditions of system dynamics in the case of a sudden disturbance or risk [28]. These phases are growth or exploitation $(r)$, conservation $(\mathrm{K})$, collapse or release $(\Omega)$, and reorganization $(\alpha)$ (Figure 4 ).

(i) Growth or exploitation (r) is the process of rapidly initiating the exploitation of resources through expanding new opportunities for the collapsed old systems. The (r) phase is a transitory phase of the systems after collapse. Thus, the system does not emphasize high stability. However, the system structure becomes more diverse due to accumulation, while more new connections between networks are accomplished. 
(ii) Conservation $(\mathrm{K})$ is the phase where the system becomes mature. Therefore, the system is slowly growing, and all entities are entered in the system. Thus, the system starts the maintenance process of the existing mature structure. The networks in the system are progressively connected. Thus, the system is in the locked-on condition and does not build a novel structure. It demonstrates less flexibility, more vulnerability, and more stability.

(iii) Collapse or release $(\Omega)$ is the phase where the external environment poses high stress on the system structure, function, and identity, and it forces the system to collapse. Here, the connectivity between the system elements is highly weak, and the accumulation of stored resources is mainly released. Therefore, the system enters into the phase of creative destruction within a short period of time. Thus, revolution could drastically occur in the system.

(iv) Reorganization $(\alpha)$ is the phase after the system collapses due to the perturbation. The system state enters into a new stability state through the reorganization (beginning) process.

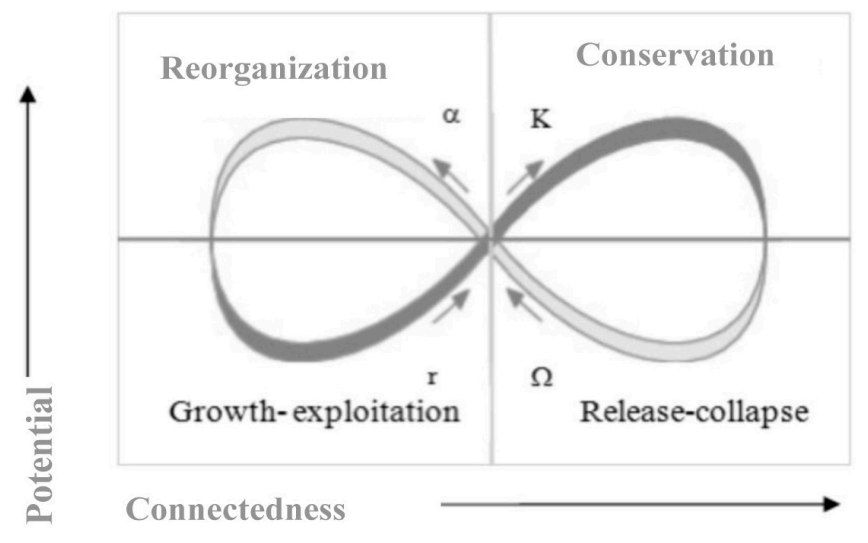

Figure 4. Conceptual representation of the adaptive cycle.

In the adaptive cycle model, the metaphor of transformation is presented as fore-loop and back-loop. The fore-loop, as the first, is the phase from $\mathrm{r}$ to $\mathrm{K}$ and represents the progressive growth in the system. The system is slow at the phase of fore-loop. The second, back-loop, is the phase from $\Omega$ to $\alpha$, and it represents the system renewal. The system is in rapid reorganization for renewal that provides the adaptive capacity for the system resilience [28]. The system in $\alpha$ phase for renewal indicates (a) to move the thresholds away, (b) to keep the system away from the thresholds, or (c) to drive thresholds more difficult to achieve regime shifts by running cross-scale interactions between system components [5].

Since cities are constantly in the process of transformation, cities as self-organizing resilient systems need to be able to afford a cyclical adaptation to change, and the urban artifacts must be able to avoid the loss of resilience when necessary. Through the discussion of a constant change and adaptive capacity, the issue is whether the city and its artifacts can be drawn into an adaptive cycle model or whether any of these principles can be related to architecture and urban design. At the core of this approach is the city seen as a self-organizing system within the process of urban growth. In addition to this, a self-organizing city is one that ensures a socio-cultural, economic, and physical environment for organizational change and adaptation. The key aspect in forming a city within an organizational adaptation is to offer the notion of flexibility in city design and architecture.

\subsection{Hierarchical Thinking in the Adaptive Cycle}

A system is composed of individual parts that are independent but function mutually for the system whole. Therefore, every individual part in a system accomplishes progressive cross-scales or hierarchical interactions with each other as a network or chain [29]. In an adaptive cycle model, the interactions across scales are defined into two situations (the system regime) as revolt and remember to ascertain the 
metaphor of transformation between fore-loop and back-loop. In the adaptive cycle, the forces "revolt" and "remember" perform at different levels within the system at the times of change, and the system always needs to stabilize revolt and remember forces. The first, revolt, is the situation at the smaller and faster events that devastate the slower and larger ones. In a system, the small parts are very fast and lead a progressive development or organizational change for larger parts of the system. Generally, the smaller and faster parts function to start incrementally on the other parts of a particular system. Notably, the smaller parts that obtain encouraging feedback from the change start to interact with larger parts to generate the system resilience. This process is mainly influenced by the revolt force, and the system is innovative and positive to test and experience new ways to allow change. The revolt indicates an internal organization both in smaller and larger parts and also enables the system to investigate long-term resilience. When a system is in revolt, the smaller parts create new opportunities to increase the system capability for adaptation. The second, remember, is the situation at larger and slow events that establish a conservative force when a system cannot overwhelm the change and uncertainties are established. In the case of remember, the system accomplishes a critical consideration to the change. A system under the influence of remember is functionally and structurally in a well-conserved situation, and it might not allow the system to accumulate a new stability and certainty [30]. When a new stability is rejected and new capabilities to accumulate resilience are not formed, the system is at risk of deterioration in the current organization. Significantly, the remember force includes a collected memory of successful tests and experiments of the past. The smaller parts progressively inform the accumulated memory of the system with the help of the remember force. Therefore, the revolt and remember relations in a system are essential to achieve a resilient development (Table 2).

Table 2. Revolt and remember cross-scale interactions.

\begin{tabular}{|c|c|c|}
\hline & Revolt & Remember \\
\hline scale /size & Small & Large \\
\hline speed & Fast & Small \\
\hline force & $\begin{array}{l}\text { Progressive } \\
\text { - innovative and positive to test and } \\
\text { experience new ways to allow change }\end{array}$ & $\begin{array}{l}\text { Conservative } \\
\text { - does not allow the system to accumulate a new } \\
\text { stability and certainty }\end{array}$ \\
\hline function & Internal organization & Accumulated memory \\
\hline
\end{tabular}

Cities fundamentally grow from the bottom up through an organizational order between interconnected parts [31]. They accomplish a large-scale complex artifact. The integrity of the bottom-up is not controlling or stopping the growth toward uncertainty of change but predicting the behavior of development or transformation by focusing on smaller scales. The bottom-up thinking infers a number of urban processes. However, self-organizing conceptions up until now would seem to suggest a comprehensive urban development is dependent upon top-down planning. The top-down planning vision had limited benefits and did not allow for engaging with processes at smaller scales. The parts of a city must be seen in the role that operates organizational structuring processes for a self-sufficient whole [31]. A self-sufficient city reveals the ability for persistency in its function/identity/structure through fast changes of urban growth. In order to attain persistency, the processes infer the interdependent scale-relations. That means the city, as a self-sufficient organism, is not scale-free. It is in the high level of multilevel hierarchical interactions, with a high degree of connective interplay between scales of parts. That implies holistic system thinking utilized the two-way interactional connectivity between different spatio-temporal scales-from bottom-up and top-down [32]. Into this, observations at small-scale indicate essential opportunities to explore cross-scale interactions. The observation at smaller scales is important to understand the processes operated at a larger scale. Likewise, it is important to identify how the large scales communicate with smaller scales. In the sequence of these two-way interactions, the smaller scales of parts are in the role of determining the data about the generated processes for self-sufficiency or the shift from a persistent to non-persistent 
structure. Hence, the abrupt changes at smaller scales ensue frequently in a short time period, due to the fast variables being more dominant than the slow variables in the system structure. That means that change is faster at smaller scales than larger scales. Therefore, change appears slower over a long time period. In the structure of a city, top-down planning control emerges when several bottom-up events occur to drive essential dynamics to organize the system for shorter periods [33]. Thus, at a large scale, disturbance is the result of the cascading phenomenon of the fast changes (non-persistence structuring processes) in smaller scales [34]. Therefore, small-scale observations are crucial to explore urban growth dynamics.

\section{Metabolic Adaptive Cycle}

The Cold War was an important era for Japan. The impact of the Cold War seriously affected the lives of the Japanese society [35]. During the 1950s and 1960s, the Japanese urban system drastically changed. The technology and the economy developed rapidly, and several environmental crises such as the impact of urban transformation emerged [36,37]. The main struggle was to find new ways of re-building their lives from an environment of catastrophe. The built environment was seen as a major motivation to (re)-construct their cities as a reflection of the atom age [38,39]. Architecture was one of the major components in the implementation of a new life and environment for Japanese society. The principle of architecture was defined as a social mission and a public realm [40]. Therefore, in1960, an architectural manifesto named Metabolism 1960: The Proposals for New Urbanism was introduced by a group of significant designers and architects at the World Design Conference in Tokyo [41]. They progressed with the vision of manipulating the mass destruction of the urban environment as a motivation to (re)-think and (re)-design the future cities toward "resolving the problem of the maladjusted man" [12,42]. The main concern was to (re)-build the future cities of Japan as a social revolt (Gardner, 2011). A complete transformation for society was acquired, and the city was determined as an environmental device of a social system that has the entire capability for adaptation to change [39].

Cities grow, and while they grow, they change and adapt themselves. In the social-metabolism concept that Burgess developed for cities; the process of growth and transformation were determined as normal, and continuous periods of development [43]. Influenced by the Burgess social metabolism concept, Metabolism promoters refused to model the city as a perfect stable image. Their schemes promoted the city as a self-organizing system, which allows for coping with change but also continuously transforming itself into a cyclical adaptation according to the changing needs of society $[35,44,45]$. According to the Metabolists, the city should be able to repair itself and disclose an organizational adaptive ability to address the unpredictable changes in conditions of urban catastrophe [46,47].

Cities present a metaphoric process of changeability through growth, release, and reorganization [48-50]. Meanwhile, the land and urban artifacts are constantly in complex but inter-reliant interactions across different scales (streets, districts, neighborhoods, suburbs, and metropolitan regions). For Tange, the urban structure of a city is likened to a network or chain, and its vitality initiates a progressively developing spatial structure. In contrast to "the city in a stability state" ideology of the modernist period, Tange incorporates the concept of multiple stability for cities. A city seen as having multiple stability pursues internal renewal to providing the ability to adapt to urban growth. Each and every component is independent, but they pursue cross-scale interactions with each other. In his plan for Tokyo Bay, an open-city plan was proposed to allow for the multiplicity (multiple-stability) of the urban structure [42]. Into such a notion, two domains were incorporated as shorter cycles and longer cycles [51]. Based on Tange's standpoint, the shorter cycles are the fast changes appearing at the smaller scales of urban clusters. They are the parts forming the whole. The long cycles are the slow changes structured at larger scales (urban clusters) to be inherent in long-life duration.

In Tange's studio project at MIT, the growth and change aspects are amalgamated to external growth- internal regeneration affiliation. From internal regeneration to external growth, a specified correlation between urban spaces and architecture is polarized in the idea of large and small scales 
of a city. The studio consulted such a proclamation of the city growth to a process-oriented cyclical adaptation, which envisioned the city as a self-organizing system. However, at the heart of all of his works, the metabolic adaptive cycle approach is present. Nevertheless, into this symbolism, a critical architectural language is determined by Tange for formulating a new relationship between the part and whole. In fact, the architecture was sought as the key component of the system that could designate cyclical adaptation for urban space, which is determined as system revolt.

Two particular quadrants are maintained-for parts, transient elements, and for whole, permanent element [43]. Tange imposed permanent urban clusters as larger scale elements of the system, which is self-organizing by transiently acting on an architectural system at smaller scale. Transient elements are thought of as regenerative magnets asserting flexibility under change and consult a higher level of adaptation. Adaptation provides an allied bond for allowing permanency for urban clusters. While Tange transformed an instrumental architectural language into a symbolic cycle, Kurukawa sought to transform symbolic metaphor to practice by defeating the flexibility of Tange's architectural language [51]. According to him, establishing individual flexibility into an architectural language enables adaptability and internal regeneration. In addition to Kurukowa's approach, Kawazoe critics describe the term prototype for sustaining internal regeneration in architectural language. For a systematic integration between architecture and urban clusters, prototype architecture is seen as possible with replaceable individual spaces, such as adding, subtracting, removing, and enlarging [36,52]. In the "Emerging Complexities" essay of Asada (1997), complexity in the self-organizing city was demarcated as a simple system of hierarchical interaction (cross-scale interaction) between the transient and the permanent elements. In detail, the hierarchical inclusion between the parts and the whole narrates the process of adaptability into an inter-reliantly cyclical pathway [38].

\subsection{Architecture as a Symbol of Transient Element}

In the CIAM 8 agenda of 1955, Kenzo Tange presented the first metabolism project, the Hiroshima Peace Centre and Memorial Park. Behind the proposal the civic core of the city is dramatically allied to the heart of the city [53]. In 1958, under the influence of Kange's Hiroshima Peace Centre and Memorial Park project, CIAM 9 instigated a biological analogy in architecture through exploring "changeable systems." A very broad platform is given to Kikutake's Sky House Project. The project introduced initial hints assessing a biological analogy into an architectural formulation at local scale. The goal of the project evokes domestic architecture as the fastest and smallest form (part), preparing an adequate adaptability source for the city (whole) to self-organize. Kikutage's Sky House project drastically models the metabolic cycle in his architectural invention by stabilizing changes with the aid of temporary spaces, which were designed around the permanent spaces. In their spatial organization, these spaces are subspaces, such as children's rooms, kitchen, storage and bathroom. They demonstrate the ability for replacement, removal or addition whenever it is needed. In a broader sense, Kikutage designates architectural ruling as flexible, but an organized order by enlarging or reducing the space. Into this, the change and future needs could be facilitated in architectural space [54]. We describe this as "move-nets," which are the transient elements assessing the spatial revolt process in the function and form of the house. They are in the form of volumetric clustering, which provide flexibility for interchangeability of space. In this way, they impose a programmatic exchange and a structure that provides a generous adaptability for growth [55]. In other words, they play a significant role on organizing a nested set of relations between building and growth.

At the World Expo in Osaka, 1960, the Takara Beautilion Pavilion encapsulated the metabolist approach. The pavilion invents a potential for horizontal or vertical stainless-steel cores for urban expansions with advancements in high technology. A number of prefabricated removable/attachable capsule units are installed to the pipes, where these units are designed as the cells of a living organism. Since "capsule cells" are capable of being attached or removed, again based on the changing needs of society, the flexible capsule cells structure of the urban pattern through expansion or shrinkage in an organizational form open joints of pipes $[56,57]$. The prefabricated flexible capsules organize 
internal regeneration in external growth. With the impact of open joints of pipes, the capsule cells at domestic scales prepare higher levels of adaptation. The higher level of adaptation is thought a potential source to set up self-containing growth. This is not only for the physical built environment but also allows metamorphosis at a life/cultural level of society. Indeed, capsules aggregate the system into longer life spans of large-scale construction as urban clusters through growing urbanism and increasing population.

The capsule architecture - as living cells of a living organism - in the Takara Beautilion Pavilion highly influenced Kurokowa's designs. He explored the capsule spaces in a cyclic development path. The cyclic path vitalizes the city under biodynamic interpretation as a growing, transforming, and dying organism. In the Nagakin Capsule Tower, capsule architecture is established as prototype architecture of metabolic cycling for reorganization. The capsule architecture is seen by Kurokowa as the form with the most architectural potential, which creates opportunities for innovation and change. The capsules are flexible objects formulating a large memory of adaptation to mega-structural urban clusters in phases of urban growth. Thus, capsules provide innovative living units. The Nagakin Capsule Tower is the only realized Metabolist project that, in practice, aimed to qualify the conceptualization of the city as a self-organizing system; an adaptive process to urban growth. Indeed, the Nagakin Capsule Tower is the only applied symbol of Metabolism [58]. The project involves challenges of the metabolic cycle; namely, whether mass production can express a new quality for a self-organizing resilient city [57]. The building asserts diverse experimental connections through internal regeneration of a new lifestyle and architectural identity. As Metabolist design proposes a mega-structural city look reflecting the latest high technology, the tower elucidates organically organizing a structure of modular capsule cells. Each module architecturally demonstrates a "plugged-in" ability rotated at varying angles around the central core [58] (Figure 5). Since one person could live in one capsule cell, the inner spatiality of each space can be interconnected with other capsules. In other words, the combinations of capsules also indicate flexibility to create larger spaces. In this way, each of them utilizes flexible joints elucidating essential adaptability and replacement [49]. Kurokowa used the potential of high technology for attaching the capsules around the core.

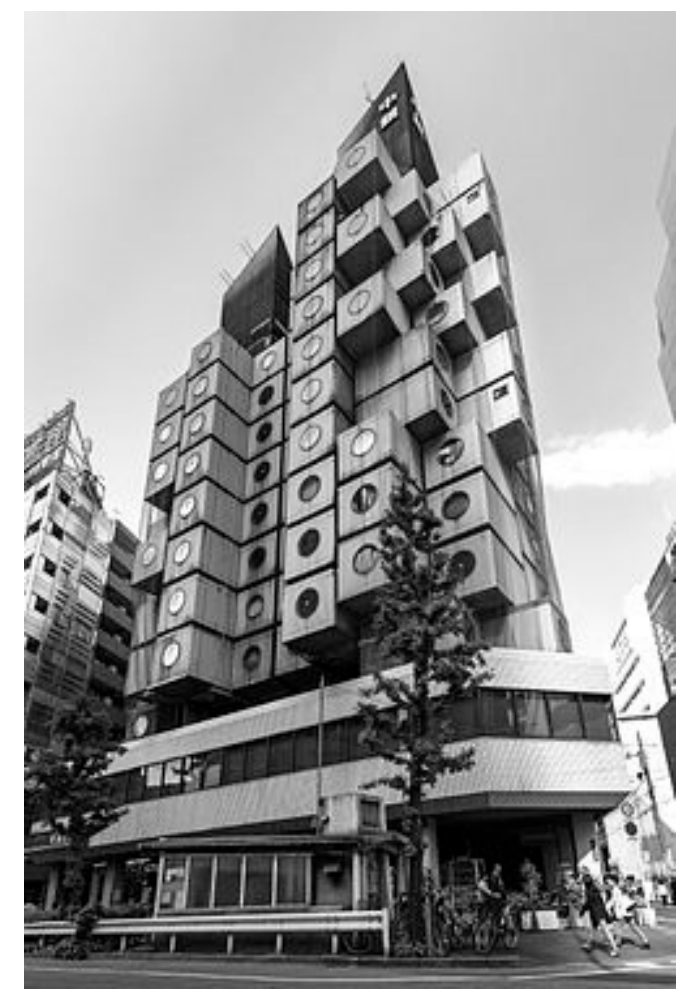

Figure 5. Nagakin Capsule Tower by Kurokowa [59]. 
With a strong linkage to Kikutage's and Tange's move-nets and plugged-in capsule cells, Maki investigated the vision of "collective/group form" in order to indicate an architectural organism organizing itself under the condition of growth and change [60]. In fact, Maki links the basis of his vision to the self-organizing mega-form approach of Metabolism. Maki recalled the Metabolism compositional form in order to picture the urbanity through architecture-human experience-context relations [61]. In the essay "Investigation in Collective Forms" by Maki and Otaka (1964), "a group form" notion asserts a fusion of more flexible forms of urban planning [60]. To better accommodate the changing requirements of the contemporary city, Maki and Otaka explore the relationships between the whole and the parts of the system upon enduring a bottom-up approach in architecture and urban planning [62]. The approach signifies asserting permanent space at longer cycles through establishing a collective system of generative elements of architectural space [60]. These generative elements are the innovative transient parts. They function to correlate a contextual adaptable connection at larger scale and also a humanistic experience while the city organically grows [63].

An artificial city of compositional homogenous clusters endorses a hierarchical set of spaces, which are the flexible foils of Metabolism. On the proposed artificial land, the formal organization of public spaces is settled on the ground, while private spaces are settled on top floors. A grouped form of architectural spaces allows any innovation as adding, enlarging, or removing based on the needs of individuals.

\subsection{Urban Space as Symbol of Urban Growth}

The spatial urban structuring of the Metabolism movement was not about envisioning a novel public transformation system or an urban infrastructure or street network [46]. According to the new urbanism critiques of the Metabolism movement, the use of landscape was seen as a key to provide crucial solutions and strategies to the problems of the growing metropolis. In particular, the design of a dynamic and free environment was seen as a first step toward shaping a relationship between individual urban artifacts (buildings) and spatial urban structure (urban clusters) and to search for the city as continuing processes of self-organization towards transformation $[64,65]$. The land sought is entirely important and also limited for urban development. This vision is underpinned by the idea of expanding and regenerating the existing city fabric with the use of potential natural landscape, such as the water and the sky, in addition to the land, whereas the most influential proposals were the floating marine structures, an urban environment of utopia created on the water, which was seen as a key to solve the problems of heavily exposed land by high costs and rapid urbanization. "The Plan for Tokyo Bay" by Kenzo Tange (1961), "Floating City-Kasugimaura" and "Helix City" by Kisho Kurukowa (1961), "Ocean City" by Kiyonori Kikutake (1962), and "Triton City" by Shoji Sadao and Buckminster Fuller (1966), as the first Metabolism's floating city proposals, showed deep awareness on rediscovering the new megalopolis and its urban quality, form, and image with (1) the artificial floating lands (which support the movement and transportation), (2) the permanent structural trunks (which consist of services, public spaces, pedestrian movement), and (3) transient plug-in structures (which consist of housing) designed by hybrid technologies that allow continuous change and renewal.

In the Tokyo Bay Plan 1960 project, the growth of Tokyo was articulated along with a linear arterial system that the physical and social aspects were hierarchically integrated within the notion of compositional totality [66]. Tange developed the urban methodology as a "master system" instead of a master plan $[13,66]$. The systematic approach emphasizes the ordered spaces in the task of hierarchical life cycles and integrated networks of functional connections. The linear artery is the new artificial environment of the master system. Therefore, the linear artery designed in the morphology opens the urban landscape that allows the structural reorganization by resolving the transient and permanent interactions through a series of interlocking modules [46]. Whereas the permanent stability in the totality scheme is constituted on the interactional flow between clustered functions, it creates a high degree of flexibility for the overall structure able to initiate the remember force to a change [67]. The hierarchy for revolt is paradoxically determined as a core system in Tange's city revolt. The core 
system in city planning is not only about capturing the city expansion but is also reorganizing the existing city pattern [65]. The core is the symbol of permanent urban clusters into a compositional totality. Over time, this monumental axis invokes urban structure to meet the flexible architectural spaces. In a broader sense, reforming the natural landscape with a huge open linear axis generates potential solutions for establishing stable and temporary architectural spaces along external growth and internal renewal. Through the concept of expandable urban forms, in the Yamanashi Communication Center project, Tange critically envisioned the city as the process of an organizational form between the permanent urban spaces and flexible transient zones. The permanent urban space was planned through 16 high-tech cylindrical towers that form the circulation system. The biological metaphor of the urban growth was based on the flexible zones that independently allow for permutation and utilization depending on the needs of future development.

At the same time as the Tokyo Bay Plan, Kurokawa moved into explaining his urban and architectural schemes targeting to create a new artificial environment for urban growth and city expansion. Since Kurokawa was one of the significant members of Tange's design team for the Tokyo bay Plan, he also had a significant role in broadening the Metabolism movement as a universal notion in the theory of architecture and urban design. For years, he made several publications explaining the theory and ideology of the Metabolism movement in international architecture magazines. In his projects Floating City (1961) and Metamorphosis (1965), the notion of freely developing urban fabric and self-contained community resulted in a patchwork-like city design. In the Floating City project, the city expansion was built on the surface of the lake, whereas the structure of the city was planned in a spiral escalator system as a "channel transportation system." A spiral escalator system contains the vertical transportation between the rooftops and lake transport system, and patchwork form helix prototypes provide continues recreation in the process of growth. The helix prototypes evoke a utopia of resilience by providing a re-creatable architectural genetic as the third order to the urban space.

Upon the influence of the Tokyo Bay Plan, Kikutake developed his own scheme for the principle of city growth. His main aim was to build artificial habitation into the sea for the development of urban communities and future cities. Along this framework, the land-sea high-tech loops relation was installed as the key domain for expansion and growth of the city [68]. In his Ocean city proposal (1963), we see that the future urban community habitation is decentralized off the seashore of Tokyo bay with floating circular islands. The ocean is proposed as a new permanent expansion enclave for a mega-structural renewal. The ocean is not determined only as a potential space to rebuild the city; it is also distinguished as a potential resource in which to live. The city in Ocean demonstrates an entire foundation for city expansion or shrinking with an increasing or decreasing number of the permanent circular floating plans. Kikutake perceives the floating plans as an adaptable form $[68,69]$. Such adaptable islands of floating plans physically and socially establish a state of balance between continuing processes via smaller fast urban artifacts and larger slower ones, which can adapt themselves to the needs of the future. In fact, the circular islands indicate an urban critique to the uncontrolled land use, and their size symbolically brings a limitation to the land use. While floating circular islands represent an integrated chain of networks (or systems), they can also cope with the increasing population growth because the new town restrains an archipelago-city typology that is able to build a self-contained community. The vision of archipelago-city typology resolves the vertical urban growth on the pre-fixed floating lands along with giant towers. The massive scaled towers define the permanent urban space by containing urban public services as urban blocks, squares, and streets and allow vertical settlement by movable housing capsules, which are the small-fast transient cells that periodically renew themselves with the plug-in ideology at cylinder hubs.

\section{Findings and Discussion}

The city is represented as a complex system that copes with change by continuously organizing itself. Based on this, the built environment was verified as the main drive, which could include all essential relations and inputs to achieve self-organization. Therefore, the built environment can foster 
new opportunities different to the stable city image. This perspective indicated that the components of the built environment are the major determinants for generating multiple-stability states within different dynamics. According to the results derived from the city proposals of Metabolism, the future city was defined in a new urban form of multiple stabilities. Two scales are revealed vital to accurately resolve cross-scale interactions in the system whole-architecture (small scale) and urban design (large scale). The interface between them is responsible for providing a cyclical adaptability (physically, spatially and functionally) to urban growth. This is for exploring emerging, but not existing, relations to interpret a city's (system's) future attributes, conditions, and needs based on changing future dynamics (social, economic, environmental). Here, there is a lack of consideration for the existing relations, especially regarding social dimensions. The reason for this failure was not the conceptualization or translation of these phenomena together with an architectural expression in the urban context, but the ignorance of the existing conditions, especially the socio-cultural dimension. The philosophical approach was solely future-oriented. Therefore, the Metabolism movement only remained as a visual design driven phenomenon for its era, although it includes innovative clues for further improvement of the self-organizing resilient city notion, especially in practice.

However, similar to the adaptive cycle of resilience theory, a metabolic adaptive cycle as a tool was created to explain the inter-reliant relation between architecture and urban design. In the context of the metabolic adaptive cycle, the transient was the given state to architecture, permanent to urban design. Based on a relational analysis, the transient (architecture) and the permanent (urban space) metaphorically performed in the same way with the revolt and remember forces of the adaptive cycle. This shows that architecture and urban design can be interfaced to indicate a spatial and functional balance (stability) between reorganization and urban growth.

The study revealed that the transient component, which when considered as architecture, imposes a significant role on accumulating the system from destruction to reorganization, while the permanent one, which is urban space, focuses conservation and urban growth.

The considered architectural proposals of Metabolism showed that the adaptive genetic in the transient component was resolved as the key feature to increase the resilience capacity of the self-organizing city. Adaptive genetic inspiration resolved the prototype architecture as the back loop of the system. In many Metabolism proposals, prototype capsule cells were formed within a modularity or collective-form identity. Hence, they were the connected/collected smaller individuals that provided more opportunities to increase the adaptive capacity for internal reorganization. Moreover, they were declared within three physical features adding, combining, or removing from the modular/collective form as a response to changing needs, conditions, and choices. Every individual was formally and functionally driven to multiple stability states among a higher level of dynamic adaptability to urban growth. Therefore, capsule cells were considered responsible for the invention, experiencing, and testing for revolt. As shown in Figure 6, the modular or collective-group form with an adaptive genetic was considered to organize an $(\alpha)$ internal adaptability for conserving $(K)$ permanent urban space to urban growth (r).

The contribution of capsule cells was not only physical but was also to enhance the adaptation of society toward any type of crisis in their lifestyles. However, there was a lack of exploration of existing needs and desires at a social dimension.

The Metabolism movement contributed to elaborate an integrative metaphoric reasoning between an adaptive transient genetic for architecture and a permanent master system at urban space for the self-organizing resilient city.

The above findings show that the Metabolism movement and the theoretical notion of self-organizing resilient systems survey an internal regeneration to external growth by pursued adaptation across scales. In order to form a grounded basis for the conception of self-organizing resilient cities, a consideration of cross-scale interactions is crucial to achieve adaptation to change. There is a strong and direct relationship between different scales preserving the system stability as a whole. We see that the adaptive cycle as a tool appears as a significant domain to determine these 
existing and emerging relations and the dynamics between them. The following table clarifies the approach of the Metabolism movement and resilience theories on rhetorical conceptualization of self-organizing systems that a city can consider when developing an efficient urban plan responding to the connection between architecture to urban design (Table 3).

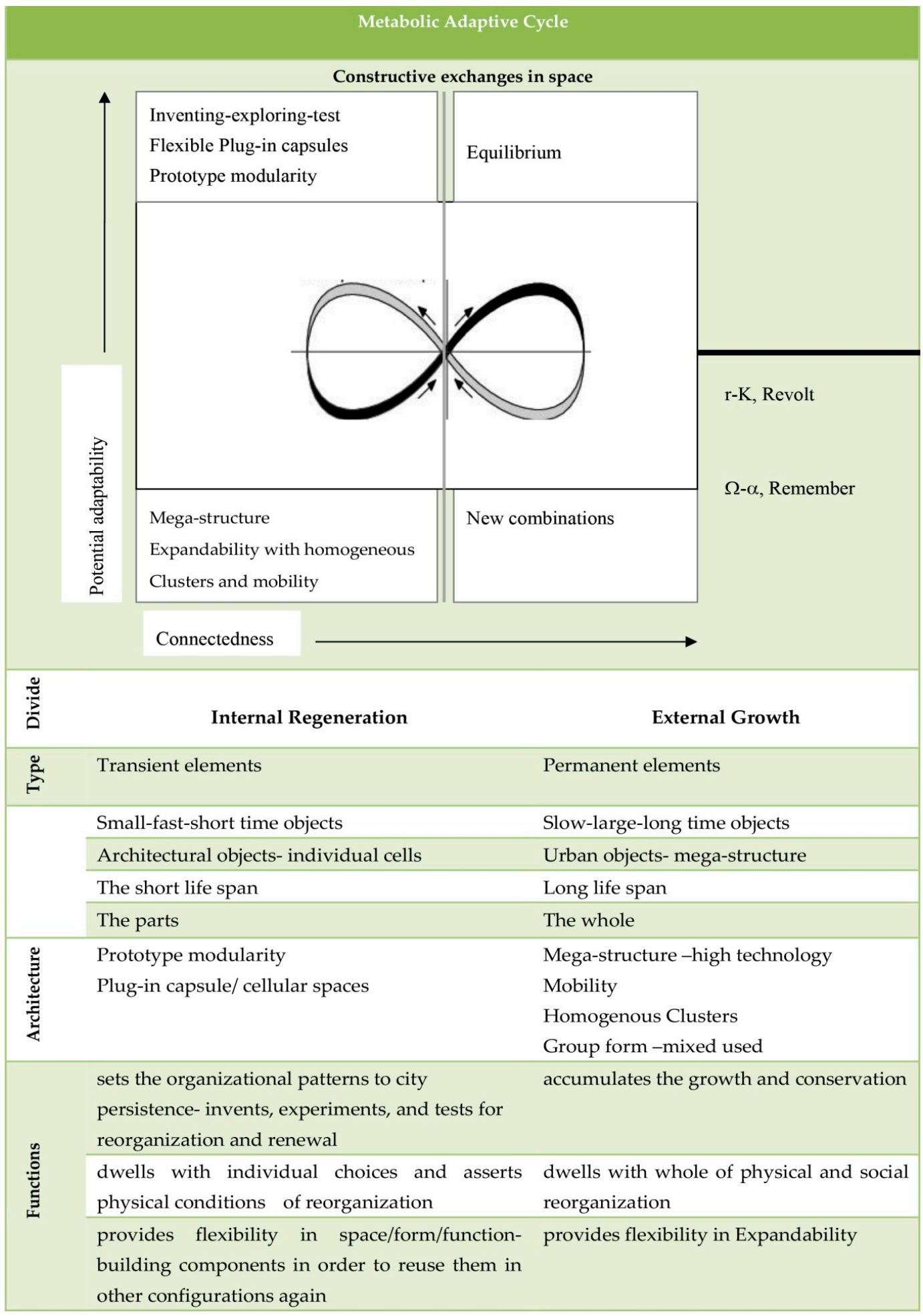

Figure 6. Metaphoric elucidation of the metabolic adaptive cycle. 
Table 3. The relationship between the Metabolism movement and self-organizing resilient systems.

\begin{tabular}{|c|c|c|}
\hline & Metabolism 1960 & Self-Organizing Resilient Systems \\
\hline Theorists & $\begin{array}{ll}n & \text { Kenzo Tange } \\
n & \text { Kiyonori Kikutake } \\
n & \text { Kisho Kurokawa } \\
n & \text { Fumihiko Maki } \\
n & \text { Masa Otaka and Noboru Kawazoe }\end{array}$ & $\begin{array}{ll}\text { - } & \text { Crawford Stanly Holling } \\
\text { - } & \text { Carl Folke } \\
\text { - } & \text { Lance H. Gunderson } \\
\text { - } & \text { Stephen Russell Carpenter } \\
\text { - } & \text { Brian Walker } \\
\text { - } & \text { Craig R. Allen }\end{array}$ \\
\hline Perspective & $\begin{array}{l}\text { The city as a self-organizing system that } \\
\text { could cope with change. }\end{array}$ & Complex systems as self-organizing systems. \\
\hline Aim & $\begin{array}{l}\text { To indicate an adaptive built environment } \\
\text { in response to urban growth and change. }\end{array}$ & $\begin{array}{l}\text { To assess self-organization feature in system's } \\
\text { behavior by responding to a change. }\end{array}$ \\
\hline Method & Theoretical & Theoretical \\
\hline \multirow[t]{2}{*}{ Findings } & $\begin{array}{l}\text { - Architecture and urban design are two } \\
\text { interrelated scales that could drive a } \\
\text { spatial balance (stability) between } \\
\text { reorganization and growth. } \\
\text { - Architecture is the essential } \\
\text { component at micro- scale for } \\
\text { re-organization of internal structure } \\
\text { independent to urban growth. } \\
\text { - } \quad \text { Adaptive genetic at architectural scale. } \\
\text { - Transient and permanent components. } \\
\text { Transient at architectural scale is for } \\
\text { indicating an internal organization by } \\
\text { experiencing, testing and innovating. } \\
\text { Permanent at urban scale is for the collected } \\
\text { (stable) memory of successful tests and } \\
\text { experiments of the past. }\end{array}$ & $\begin{array}{l}\text { Cross-scale interactions; high-degree of } \\
\text { connectivity exists between scales } \\
\text { of components. } \\
\text { Small and fast components as the key for } \\
\text { re-organization of internal structure of } \\
\text { the system. } \\
\text { Revolt and remember forces: revolt is for } \\
\text { indicating an internal organization by, } \\
\text { experiencing, testing and innovating. } \\
\text { Remember is for the collected memory of } \\
\text { successful tests and experiments of the past. }\end{array}$ \\
\hline & Metabolic adaptive cycle & Adaptive cycle \\
\hline New Influences & $\begin{array}{l}\text { Provide to explore the emerging } \\
\text { (future) relationship between } \\
\text { micro-scale/architecture, } \\
\text { and macro-scale/urban designs. }\end{array}$ & $\begin{array}{l}\text { - A cyclical adaptation is crucial for the } \\
\text { system resilience. } \\
\text { Provide to explore the existing (present) and } \\
\text { emerging (future) relationships at small } \\
\text { components and large components. }\end{array}$ \\
\hline
\end{tabular}

\section{Conclusions}

This research carried out a systematic theoretical survey and studied data to conceptualize self-organizing systems and resilience theory as a single interfaced notion at the city scale. The purpose of this study was to illustrate a theoretical framework for the conceptualization of self-organizing resilient cities by considering architecture as a fundamental scale/component in urban planning, which could anticipate adaptability at smaller scales and could perform a reorganization of the internal structure independent to urban growth. Such an effort was undertaken to elaborate the importance and the role of architecture as a corresponding scale to be considered for facilitating self-organizing resilient cities in urban planning. The research confirmed that the self-organizing of cities is rationally dependent on the resilience (adaptive capacity) of the city (system), which operates cross-scale interactions between different components and their dynamics. The research showed that architecture (as small scale) and urban design (as large scale) drive interdependent interactions to be considered for self-organizing resilient cities. However, adaptive cycle as a tool is essential to explore existing and emerging relations between architecture and urban design. Moreover, architecture is the fundamental scale that could create an adaptive genetic at smaller scales to cope with change and plays an important role for reorganizing of the system toward urban growth.

Contemporary cities have various challenges and opportunities that are completely different from the city dynamics of the past. Therefore, like every other complex system, contemporary cities 
demonstrate a high degree of complex phenomena. Planning for self-organizing resilient cities in the context of complexity phenomena can be done through emerging cross-scale planning visions, such as a master system considered through both bottom-up and top-down planning approaches, which is essential to respond to the complex structure of cities. Furthermore, a master system will encourage the internal structure as independent to urban growth and the urban growth independent to the internal structure of the city. Within the master system, architecture should be considered as the essential scale. Hence, architectural interventions appear as the smallest driving forces and have a significant influence on the formation of urban form by transmitting the dynamics of social, economical, environmental, and cultural dimensions at the small scale. Therefore, a master system that considers architecture will also encourage authorizing accurate multiple-stability states at the small scale. In addition, a holistic embodiment between architecture, urban design, urban planning, and other relevant disciplines and dimensions will be unified. Moreover, a causal adaptive cycle tool to determine the existing and emerging relations and conditions between architecture and urban design is necessary to provide appropriate inputs for urban planning in the context of self-organizing resilient systems. Furthermore, implementing adaptive genetic design-driven approaches and proposals at an architectural scale will help to increase the adaptability of the internal structure of the city. When the city generates reorganization, the adaptive genetic at an architectural scale (as the fast and smaller scale) will encourage a creative adaptive force for testing, experimentation, and innovation. However, to support an efficient self-organization, the adaptive genetic within architecture must encourage flexibility for adaptation at an environmental level but also at a social, cultural, and economic context.

In addition to the adaptive genetic aspect that has been recognized, there might be other influences that may be considered for theoretical improvement of self-organizing resilient cities. Future research needs are the translation of the theoretical notion of a self-organizing resilient city and its key parameters to practice by an indicated simulation.

Author Contributions: The article was designed and written by C.E. with the contribution of co-author R.A.A. The paper was supervised and critiqued by R.A.A. and improved by corresponding author C.E. All authors read and approved the paper.

Funding: This research received no external funding.

Conflicts of Interest: The authors declare no conflict of interest.

\section{References}

1. Holling, C.S. Resilience and stability of ecological systems. Annu. Rev. Ecol. Syst. 1973, 4, 1-23. [CrossRef]

2. Walker, B.; Holling, C.S.; Carpenter, S.R.; Kinzig, A. Resilience, adaptability and transformability in social-ecological systems. Ecol. Soc. 2004, 9, 5. [CrossRef]

3. Folke, C. Resilience: The emergence of a perspective for social ecological systems analyses. Glob. Environ. Chang. 2006, 16, 253-267. [CrossRef]

4. Portugali, J. Self-Organization and the City; Springer: Berlin/Heidelberg, Germany, 2000.

5. Roggema, R. Towards Enhanced Resilience in City Design: A Proposition. Land 2014, 3, 460-481. [CrossRef]

6. Pisano, U. Resilience and Sustainable Development: Theory of resilience, systems thinking and adaptive governance. Eur. Sustain. Dev. Netw. 2002, 26, 50.

7. Schipper, L.F.; Langston, L. A Comparative Overview of Resilience Measurement Frameworks. In Analyzing Indicators and Approaches; Overseas Development Institute: London, UK, 2015; p. 422. [CrossRef]

8. Weddle, A.E. Editorial: Landscape and Urban Planning. Landsc. Urban Plan. 1986, 13, 165-167. [CrossRef]

9. Batty, M.; Marshall, S. Centenary paper: The evolution of cities: Geddes, Abercrombie and the new physicalism. Town Plan. Rev. 2009, 80, 551-574. [CrossRef]

10. Ernstson, H.; van der Leeuw, S.E.; Redman, C.L.; Meffert, D.J.; Davis, G.; Alfsen, C.; Elmqvist, T. Urban transitions: On urban resilience and human dominated ecosystems. J. Hum. Environ. 2010, 39, 531-545. [CrossRef]

11. Hodson, M.; Marvin, S. Can cities shape socio-technical transitions and how would we know if they were? Res. Policy 2010, 39, 477-485. [CrossRef] 
12. Oliveira, F.L. Of Metabolism: Future cities for our contemporary world. Risco 2011, 14, 77-81.

13. Schalk, M. The Architecture of Metabolism Inventing a Culture of Resilience. Arts 2014, 3, 279-297. [CrossRef]

14. Shuhai, Z. Self-Organizing Urban Transformation and Its Institutional Implications. Ph.D. Thesis, University of Groningen, Groningen, The Netherlands, 2016; pp. 106-128. [CrossRef]

15. Eken, C. Learning from Resilience: Cities towards a Self-Organizing System. Int. J. Contemp. Urban Aff. 2019, 3, 92-103. [CrossRef]

16. Whetten, D.A. Modeling as Theorizing: A Systematic Methodology for theory Development. Manag. Organ. Rev. 2009, 45. [CrossRef]

17. Martin, P.Y.; Turnar, B.A. The Grounded theory and organizational research. J. Appl. Behav. Sci. 1986, $22,141$. [CrossRef]

18. Strauss, A.; Juliet, C. Grounded Theory Methodology: An overview. In Handbook of Qualitative Research, 1st ed.; Denzind, N., Lincoln, Y., Eds.; Sage Publications: Thousand Oaks, CA, USA, 1994; pp. 273-284.

19. Allan, G. A critique of using Grounded Theory as a Research Method. Electron. J. Bus. Res. Methods 2003, 2, 1-10.

20. Shield, P.; Rangarjan, N. A Playbook for Research Methods: Integrating Conceptual Frameworks and Project Management; New Forums Press: Stillwater, OK, USA, 2013.

21. Elliot, R.; Tumlak, L. Descriptive and interpretive approaches to qualitative research. In $A$ Handbook of Research Methods for Clinical and Health Physiology; Oxford University Press Inc.: New York, NY, USA, 2005.

22. Sharma, K.K.; Mediratta, P.K. Importance of keywords for retrieval of relevant articles in Medline Search. Indian J. Pharmacol. 2002, 34, 369-371.

23. Poletto, S.; Pasquero, C. Systematic Architecture: Operating Manual for Self-Organizing City; Routledge: New York, NY, USA, 2013.

24. Mahoney, J. Comperative-Historical Methodology. Annu. Rev. Sociol. 2004, 30, 81-101. [CrossRef]

25. Rowlingson, M.; Hassard, J.; Decker, S. Research Strategies for organizational history: A dialogue between historical theory and organization theory. Acad. Manag. Rev. 2014, 39, 250-274. [CrossRef]

26. Holling, C.S. Resilience of Ecosystems; local surprise and global change. In Sustainable Development of Biosphere; Clark, W.C., Munn, R.E., Eds.; Cambridge University Press: Cambridge, UK, 1986; pp. $292-317$.

27. Holling, C.S. Understanding the Complexity of Economic, Ecological and Social Systems. Ecosystems 2001, 4, $390-405$. [CrossRef]

28. Gunderson, L.H.; Holling, C.S. Resilience and Adaptive Cycles in Panarchy: Understanding Transformation in Human and Ecological Systems; Island Press: Washington, DC, USA, 2002; pp. 25-62.

29. Kauffman, S.; Macready, W. Technological Evolution and Adaptive Organizations: Ideas from biology may find applications in economics. Complexity 1995, 1, 26-43. [CrossRef]

30. Abcouwer, A.; Parson, B. Sustainable Assertiveness-The Adaptive Cycle of Resilience: Can Curiosity be Organized? 2011. Available online: http://www.adaptivecycle.nl/index.php?title=Sustainable_assertiveness_ -_the_adaptive_cycle_of_resilience (accessed on 23 May 2019).

31. Batty, M. Building a Science of Cities. Cities 2005, 29, S9-S16. [CrossRef]

32. Levin, S.A. Fragile Dominion: Complexity and the Commons; Perseus Books: Reading, MA, USA, 1999.

33. Gunderson, L. Comparing Ecological and Human Community Resilience. White Paper to Community Resilience Initiative; Carri Research Report, 5; Southeastern Regional Research Initiative, Oak Ridge National Lab: Oak Ridge, TN, USA, 2009.

34. Holling, C.S. Engineering Resilience within Ecological Constraints: Engineering Resilience Versus Ecological Resilience; The National Academies Press: Washington, DC, USA, 1996.

35. Koolhaas, R.; Obrist, H. Project Japan: Metabolism Talks; Taschen: Cologne, Germany, 2011.

36. Pernice, R. Vision of the Future from the Past. The Metabolist Movement and the Urban Utopias of 1960s. In Proceedings of the 11th International Symposium on Advanced Technology, Nagoya, Japan, 17-21 March 2012.

37. Wendelken, C. Putting Metabolism Back in Place. The Making of a Radically Decontextualized Architecture in Japan. In Anxious Modernisms: Experimentation in Postwar Architectural Culture; MIT Press: Cambridge, MA, USA; London, UK, 2000.

38. Asada, A. Emerging Complexities. In D: Columbia Documents of Architecture and Theory; Tschumi, B., Ed.; Columbia University Press: New York, NY, USA, 1997; Volume 6, pp. 80-84.

39. Cho, H.; Shin, C. Metabolism and Cold War Architecture. J. Archit. 2014, 19, 623-644. [CrossRef]

40. Tamari, T. Metabolism: Utopian Urbanism and the Japanese Modern Architecture Movement Special Section: Urban Problematic II. Theoryculture Soc. 2014, 31, 201-225. 
41. Kikutake, K.; Kawazoe, N.; Maki, F.; Ohtaka, M.; Kurokawa, N. Metabolism 1960: The Proposals for New Urbanism; Bijutsu Shuppansha: Tokyo, Japan, 1960.

42. Lin, Z. Kenzo Tange and the Metabolist Movement: Urban Utopias of Modern Japan; Routledge: New York, NY, USA, 2010.

43. Burgess, E.; Park, E.R.; McKenzie, R.D. The City; The University of Chicago Press: Chicago, IL, USA; London, UK, 1925.

44. Mori Art Museum. Metabolism, The City of The Future: Dreams and Visions of Reconstruction in Postwar and Present-Day Japan; Press Release; Mori Art Museum: Tokyo, Japan, 2011; Volume 2.

45. Lin, Z. Nakagin Capsule Tower Revisiting the Future of the Recent Past. J. Archit. Educ. 2011, 65, 13-32. [CrossRef]

46. Lin, Z. Urban Structure for The Expanding Metropolis: Kenzo Tange's 1960 Plan for Tokyo. J. Archit. Plan. 2007, 24, 109-124.

47. Gardner, W.O. The 1970 Osaka Expo and/as Science Fiction. Rev. Jpn. Cult. Soc. 2011, 28, $26-43$.

48. Daniell, T. From Far East to Middle East: Revitalizing Metabolism. J. Archit. Relat. Arts 2008, 9, 23. [CrossRef]

49. Lin, Z. Nakagin Capsule Tower and The Metabolist Movement Revisited. J. Archit. Educ. 2011, 65, 13-32. [CrossRef]

50. Lin, Z. Metabolist Utopias and Their Global Influence: Three Paradigms of Urbanism. J. Urban Hist. 2016, 42, 604-622. [CrossRef]

51. Tange, K. Kenzo Tange Associates 1946-1979; SD special issue; Prentice-Hall: Brazille, NY, USA, 1980; Volume 1.

52. Kawazoe, N. The Ise Shrine and Its Cultural Context. In ISE: Prototype of Japanese Architecture; Tange, K., Kawazoe, N., Eds.; MIT Press: Cambridge, MA, USA, 1965; pp. 165-206.

53. UrL-1. Available online: http://www.archdaily.com/477882/le-corbusier-model-for-the-metabolists (accessed on 23 May 2019).

54. UrL-2. Available online: http://archeyes.com/sky-house-kiyonori-kikutake/ (accessed on 18 June 2018).

55. UrL-3. Available online: http://socks-studio.com/2013/12/12/evolutionary-housescape-the-metabolist-skyhouse-by-kiyonori-kikutake-1958/v (accessed on 11 April 2018).

56. Kurokawa, N. Challenge to the Capsule: Nakagin Capsule Tower Building. Jpn. Archit. 1972, 47, 17.

57. UrL-4. Available online: http://www.kisho.co.jp/page/209.html (accessed on 8 April 2018).

58. UrL-5. Available online: http://www.archdaily.com/110745/ad-classics-nakagin-capsule-tower-kishokurokawa.html (accessed on 24 December 2018).

59. UrL-6. Available online: https://ofbeatjapan.org/nakagin-capsule-tower/ (accessed on 7 February 2018).

60. Maki, F. Investigations in Collective Form; School of Architecture: St. Louis, MO, USA, 1964.

61. Maki, F. Notes on Collective Form. Jpn. Archit. 1994, 16, 247-297.

62. Xi, Q. Fumihiko Maki and His Theory of Collective Form: A Study on Its Practical and Pedagogical Implications. Master's Thesis, Washington University, Saint Louis, MO, USA, 2013; p. 936. [CrossRef]

63. Pompili, M. The Structural Core as Totem: Reflections on Form and Symbol in the Architecture of Metabolism. Fabrications 2012, 21, 69-88. [CrossRef]

64. Pernice, R. The issue of Tokyo Bay's Recalimed lands as the origin of urban utopias in modern Japanese Architecture. J. Archit. Plan. 2007, 613, 259-266. [CrossRef]

65. Lin, Z. From Megastructure to Megalopolis: Formation and Transformation of Mega-projects in Tokyo Bay. J. Urban Des. 2007, 12, 73-92. [CrossRef]

66. Tange, K. A Plan for Tokyo 1960. Ekistics 1961, 12, 9-19.

67. Maki, F. Toward Group Form. In Architecture Culture 1943-1968; Ockman, J., Ed.; A Documentary Anthology; Rizzoli: New York, NY, USA, 2005; p. 324.

68. Oshima, K.T. Kiyonori Kikutake: Between Land and Sea; Lars Muller Publishers: Zürich, Switzerland, 2016.

69. Nyilas, A. On the Formal Characteristics of Kiyonori Kikutake's 'Marine City' Projects at the Turn of the 50's and 60's Architecture Research. Archit. Res. 2016, 6, 98-106.

(C) 2019 by the authors. Licensee MDPI, Basel, Switzerland. This article is an open access article distributed under the terms and conditions of the Creative Commons Attribution (CC BY) license (http://creativecommons.org/licenses/by/4.0/). 